Zealand. Norway clearly has the most efficient system -the proportion of unsatisfactory calls for which the system could be blamed was only 3 per cent, against 9 per cent in the UK and 11 per cent in New Zealand. In Britain, trunk calls were twice as likely to go astray as local calls-nearly 20 per cent were unsatisfactory because of the failure of the system. This, the report points out, is not because the equipment is old and out of date-the failure rate on modern exchanges is much the same as that on pre-war exchanges. The fact is that too little equipment has been provided, so that exchanges are often swamped with calls. When this happens, callers get the engaged signal; it seems that about one-third of the engaged signals are caused in this way, the other two-thirds representing genuinely engaged lines.

The only way to get around this difficulty is to supply more new equipment which, the GPO says, means higher telephone charges. The Prices and Incomes Board found that productivity in the telecommunications side of the GPO had been increasing at a rate of more than 8 per cent per year, and was satisfied that no important improvement could be made in time to avoid a price increase. In the next three years, the GPO is intending to spend $£ 1,100$ million on investment in telecommunications; in order to do this, and to make the target return of 8.5 per cent on net assets, increases in prices were inevitable. Subscribers will have to suffer now if they are to get a better system later. In the longer term, the GPO should be wondering how to increase the number of subscribers-compared with other developed countries, Britain still has very few telephones-183 telephones per 1,000 of population in Britain, against 459 in the USA and 440 in Sweden.

\section{Measuring Aptitude}

INVESTIGATION into supplementary predictive information for university admission is the carefully worded. title of the project set up in 1966 by the committee of vice-chancellors to examine academic aptitude tests for university entrants. While various working parties and councils discuss the entire structure of the sixth form curriculum, the vice-chancellors' investigation is an attempt to provide for more education and less cramming under the existing A-level examination system. Academic aptitude tests would provide information for university selectors on candidates' general ability to think effectively and would supplement the assessment of knowledge provided by A-level examinations. In this way the aptitude tests should remove some of the pressure to cram from the A-level courses.

Recommendations for tests of this kind were made in the Robbins report in 1963 and, although the vicechancellors took three years to set up the investigation, in such matters it is a question of better late than never. The project is being financed by grants from the Department of Education and Science and the Schools Council for an initial four year period, and the first tests were made in 1967. The experimental aptitude test being used in the project is based on a multiplechoice, objective type of test developed by Professor R. A. C. Oliver of the University of Manchester. This in turn evolved from tests of this kind which have been used successfully in the United States for 40 years. Numeracy and verbal ability are the two main factors which are assessed. It is hoped that the tests will measure general ability, not facility in particular subjects, and will therefore be useful in assessment of candidates who want to read a subject at university which they have not studied at school. Aptitude for arts or science should also be indicated. Sixth formers who are not very elever but who have had good teaching, and those who are very bright but have not been well taught, are likely to be misjudged if assessed by A-levels alone, so it is hoped that aptitude tests will show them in their true light.

Experiments with tests of this kind are inevitably slow, because the results cannot be judged until the first sixth formers who are tested have finished their university courses. To save on time on the first series, a number of first year undergraduates were tested last October. In all, 37,000 tests were given, although not all the sixth formers are likely to go to university. This year, 20,000 sixth formers who are intending to apply to university will be tested. As a guard against prejudice or contamination of the sample, the results of the tests are being kept entirely confidential. If useful tests can be developed from this project, and the system becomes operational for the whole of Britain, the results will probably be made available to schools as well as to the university selectors. Because the tests do not depend on a syllabus, they could be given at the beginning of the fourth term in the sixth form, and with the help of marking machines the results could be with the university selectors in good time.

The results could be helpful to schools in that teachers would know whether their personal assessments of students are in line with general standards. No definite policy has yet been formulated on the question of whether the sixth former should be told the results of his test. If the tests indicate an aptitude in a particular direction, it would be useful and only fair for candidates to be told their results, for this might affect their choice of university subject. If and when broader curricula are introduced, and the option for arts or science remains open throughout the sixth form, advice on aptitude might be even more welcome than at present. If continuous assessment of pupils by their teachers is introduced instead of A-level examinations, then academic aptitude tests administered by a single body would be one way of maintaining uniformity of standards.

\section{University Statistics}

THe latest volume of statistics collected by the University Grants Committee from universities in Britain (Returns from Universities and University Colleges, 1965-66. Cmnd. 3586, HMSO, £1) is more than twice the price of its predecessor, but, to compensate, it is nearly four times as big-192 pages instead of 54 . These Returns have been published comparatively much later than earlier issues. The 1964-65 statistics, for example, were out by October of the following year. The latest statistics have been delayed by a further six months. This delay, however, may be a result of some changes in the collection of university statistics introduced in the academic year 1965-66. For example, the timing of the count of staff and student numbers was changed so as to bring it into line with the pattern used in all other sectors of educational statistics. In previous years the count took place at the end of the academic year; in 1965-66 the 